\title{
Correction to: On the Lark-Horovitz equation for ion selective membrane electrodes and its derivation
}

\author{
Dmitri P. Zarubin ${ }^{1}$
}

Received: 30 October 2017 / Accepted: 2 November 2017 / Published online: 14 November 2017

(C) Springer-Verlag GmbH Germany, part of Springer Nature 2017

\section{Correction: J Solid State Electrochem} https://doi.org/10.1007/s10008-017-3744-7

In the published article, eq. 16 is misprinted. Correct equation is as follows

$$
\begin{aligned}
\mathcal{E}= & \left(\nu_{\mathrm{e}} z_{\mathrm{e}} F\right)^{-1} \sum \nu_{\mathrm{R}} \mu_{\mathrm{R}}-(F I)^{-1} \\
& \times\left(\int_{\mathcal{L}} \sum \tau_{k}^{\mathcal{L}} \vec{j} \cdot \vec{\nabla} \mu_{k} \mathrm{~d} V+\int_{\mathcal{M}} \sum \tau_{k}^{\mathcal{M}} \vec{j} \cdot \vec{\nabla} \mu_{k} \mathrm{~d} V\right)
\end{aligned}
$$

The author and the Springer-Verlag apologise for this misprint and any consequent inconvenience to readers.

The online version of the original article can be found at https://doi.org/ 10.1007/s10008-017-3744-7

Dmitri P. Zarubin

dmitri.zarubin@mtu-net.ru

1 Moscow State University of Technology and Management, 73

Zemlyanoi Val, Moscow, Russian Federation 109803 